\title{
A comparative study of incidence and severity of nasal complications while using nasal prongs and nasal mask as CPAP interface in preterm neonates: A Randomized Control trial
}

\author{
Dubey A. ${ }^{1}$, Malik S. ${ }^{2}$, Sneha Prakash ${ }^{3}$ \\ ${ }^{1}$ Dr. Archana Dubey, Professor, ${ }^{2}$ Dr. Sunil Malik, Assistant Professor, ${ }^{3}$ Dr. Sneha Prakash, Junior Resident; all authors \\ are affiliated with Department of Paediatrics, Subharti Medical College, Meerut, UP, India.
}

Corresponding Author: Dr. Sunil Malik, Assistant Professor, Department of Paediatrics, Subharti Medical College, Meerut, India. E-mail: drneelmalik@gmail.com

\begin{abstract}
Objective: To compare the incidence and severity of nasal trauma while using nasal prong and nasal mask as CPAP interface in preterm neonates. Material and Methods: A comparative study was conducted on preterm neonates (28-34 weeks gestation) with respiratory distress, who were admitted in neonatal unit in a tertiary care level hospital. These babies were randomized and divided into two groups while being put on bubble CPAP, using either nasal prongs (Group A) or nasal mask (Group B) as interface. The data was collected and analyzed for nasal trauma among both groups. Result: It was observed that there was no significant difference in the overall incidence of nasal trauma in both groups. Mild trauma was more common in babies received nasal CPAP via mask, while severity of trauma increases with use of bi-nasal prongs. Conclusion: Bubble continuous positive airway pressure with bi-nasal prongs as interface is as effective as nasal mask but causes more severity of nasal trauma.
\end{abstract}

Keywords: Neonates, CPAP, Nasal Prongs, Nasal Mask, Nasal trauma

\section{Introduction}

Respiratory distress in newborn babies is one of the commonest causes of Neonatal intensive care unit (NICU) admissions (30-40\%) [1]. Bubble CPAP is a simple, cost effective and non-invasive method of ventilating sick newborns [2]. It is a well-established mode of respiratory support in preterm babies. Early use of CPAP for stabilization of at-risk preterm infants reduces ventilator needs. Nasal prongs and nasal masks are being frequently used as interface between patient

\section{Materials and Methods}

Study design: Randomized control trial, Open label and CPAP device specially in resource limited settings. Nasal prongs and nasal masks both are associated with mild to severe nasal trauma in preterm neonates [3]. There is limited data available for grading and severity of nasal trauma during CPAP therapy hence, we designed this study to compare the local complication associated with use of nasal prong and nasal mask interfaces in preterm infants on CPAP support.

Setting of study: This study was performed between October 2016 to February 2018 at neonatal care unit in a tertiarycare hospital in western Uttar Pradesh

Inclusion criteria: Preterm babies of gestational age 28-34wks with moderate respiratory distress (according to Silverman score) admitted within 6 hours of life, requiring CPAP, were enrolled in the study after getting informed written consent.

Exclusion criteria: Babies with 5-miute Apgar scores <5, major congenital malformation/ anomalies, severe sepsis/ meningitis/ metabolic disorders were excluded from the study.

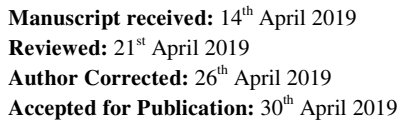




\section{Original Research Article}

Ethical clearance: The study protocol was approved by the Ethics Committee of the institute.

Sample size: The sample size calculated was 93 as per formula.

$$
\mathrm{n}=\frac{4 \sigma^{2}}{\mathrm{E}^{2}}
$$

$\left(\mathrm{n}=\right.$ sample size,$\sigma^{2}=(\text { standard deviation })^{2}$ or Variance, $\mathrm{E}=$ Least permissible error $)$

Collection of data: After initial stabilization the treatment plan was delineated. Babies requiring bubble CPAP support were randomized by using Tippet's random number table to one of the two groups according to the interface used to provide CPAP (Group A: Binasal prongs, Group B: Nasal mask). Scoring for severity of respiratory distress in preterm babies was done by using the Silverman Anderson score (SAS) [3]. Nasal trauma was assessed when the interface was transiently removed for suctioning or cleaning. [Figure 1]

Grading system: A classification was designed by the research team to grade nasal trauma during CPAP therapy for the study. This was based on degree of trauma at the local site:

- Grade I (Mild trauma) - erythema, tenderness or color change of skin/ mucosa/ nasal septum

- Grade II (Moderate trauma) - excoriation, crusting, bleeding or induration of skin/ mucosa/ septum

- Grade III A (Severe trauma) - narrowing of the passage/ necrosis of skin/mucosa/ septum

- Grade III B (Severe trauma) - Septal perforation

- Grade IV - Barotrauma

Statistical analysis: Data was collected on structured Performa and managed using MS Excel software. Statistical analysis was performed using one-way ANOVA-F test at $1 \%$ level of significance. Statistical significance was considered if the $\mathrm{p}$ value was $<0.01$. The quantitative data was expressed in mean $\pm \mathrm{SD}$ and qualitative data was expressed in terms of frequency distribution.

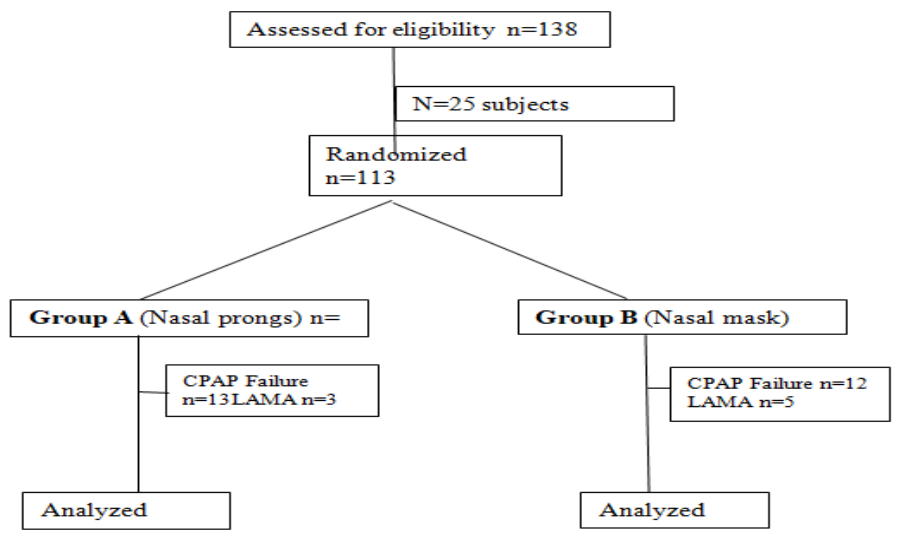

Figure 1: Flow chart of the study

\section{Results}

A total of 138 preterm babies were assessed for eligibility to the study: 25 newborns were excluded from the study as they did not meet the inclusion criteria. A total of 113 babies were enrolled in the study out of which 25 babies were ventilated due to CPAP failure and 8 babies left against medical advice before the study could be completed, hence were excluded.Finally 80 subjects completed the study. 41 subjects were enrolled in group A (nasal prongs) and 39 in group B (nasal mask). The baseline characteristics of both groups were comparable to each other [Table1].

Overall incidence of nasal trauma was46.34\% (19/41) babies in group A (bi-nasal prongs) and 43.58\% (17/39) babies in group B (nasal mask) during CPAP therapy ( $\mathrm{p}=0.537)$. Grade I trauma was seen in $3(7.31 \%)$ babies in group A and 9 $(23.07 \%)$ in group B (p value - 0.0018). Grade II trauma was noticed in $9(21.95 \%)$ in Group A and 8 (20.51\%) in group B ( $p$ value - 0.4017). Grade III trauma was seen in $7(17.07 \%)$ babies in group A and none in group B (p value =0.0001). No cases of septal perforation or Barotrauma were observed in both groups [Table 2]. 
Original Research Article

Table-1: Comparison of general characteristics of study subjects.

\begin{tabular}{|c|c|c|c|}
\hline Baseline parameters & $\begin{array}{c}\text { NASAL PRONGS } \\
(n=41)\end{array}$ & $\begin{array}{l}\text { NASAL MASK } \\
\quad(\mathbf{n}=\mathbf{3 9})\end{array}$ & $p$ value \\
\hline $\begin{array}{c}\text { Gestational age, in weeks } \\
\text { mean }\left(\mathrm{SD}^{*}\right)\end{array}$ & $30.475 \pm 2.018$ & $30.245 \pm 2.021$ & 0.8950 \\
\hline Birthweight (gm) & $1180 \pm 0.22$ & $1182 \pm 0.21$ & 0.7554 \\
\hline $\begin{array}{l}\text { Sex }(\mathrm{n}) \\
\text { Male } \\
\text { Female }\end{array}$ & $\begin{array}{l}31 \\
10\end{array}$ & $\begin{array}{l}26 \\
13\end{array}$ & $\begin{array}{l}0.0984 \\
0.2334\end{array}$ \\
\hline $\begin{array}{c}\text { Mode of delivery }(\%) \\
\text { Vaginal } \\
\text { Cesarean }\end{array}$ & $\begin{array}{l}78.04 \\
21.95\end{array}$ & $\begin{array}{l}69.23 \\
30.76\end{array}$ & $\begin{array}{l}0.4221 \\
0.4996\end{array}$ \\
\hline $\begin{array}{c}\text { Place of delivery (\%) } \\
\text { Home/Institutional }\end{array}$ & $24.39 / 75.60$ & $30.76 / 69.23$ & - \\
\hline $\begin{array}{l}\text { Assessment of Respiratory Distress/ } \\
\text { Silverman score (\%) } \\
4 \\
5 \\
6\end{array}$ & $\begin{array}{l}31.70 \\
29.26 \\
39.02\end{array}$ & $\begin{array}{l}30.76 \\
33.33 \\
35.89\end{array}$ & - \\
\hline $\begin{array}{l}\text { Surfactant Instillation }(\%) \\
\text { Surfactant received } \\
\text { Surfactant not received }\end{array}$ & $\begin{array}{l}53.65 \\
48.78\end{array}$ & $\begin{array}{l}58.97 \\
41.02\end{array}$ & $\begin{array}{l}0.781 \\
0.720\end{array}$ \\
\hline $\begin{array}{c}\text { Administration of Antenatal steroids } \\
(\%) \\
\text { Given } \\
\text { Not Given }\end{array}$ & $\begin{array}{l}34.14 \\
68.29\end{array}$ & $\begin{array}{l}46.15 \\
53.84\end{array}$ & - \\
\hline
\end{tabular}

*SD: standard deviation

Table-2: Comparison of nasal trauma during CPAP therapy.

\begin{tabular}{|c|c|c|c|c|}
\hline S. No & Grade of trauma & $\begin{array}{c}\text { Group A } \\
(\text { nasal prongs }) \\
\mathbf{n = 4 1}(\mathbf{\%})\end{array}$ & $\begin{array}{c}\text { Group B } \\
(\text { nasal mask }) \\
\mathbf{n = 3 9}(\mathbf{\%})\end{array}$ & p value \\
\hline $\mathbf{1 .}$ & Grade I (Mild trauma) & $03(07.31)$ & $09(23.07)$ & $\mathbf{0 . 0 0 1 8}$ \\
\hline $\mathbf{2 .}$ & Grade II (Moderate trauma) & $09(21.95)$ & $08(20.51)$ & 0.4017 \\
\hline $\mathbf{3 .}$ & Grade III A (Severe trauma) & $07(17.07)$ & $00(00.00)$ & $\mathbf{0 . 0 0 0 1}$ \\
\hline $\mathbf{4 .}$ & Grade III B (Septal Perforation) & 00 & $00(00.00)$ & 00 \\
\hline $\mathbf{5 .}$ & Grade (Barotrauma) & $00(00.00)$ & $00(00.00)$ & 0.00 \\
\hline & Total & $19(46.34)$ & $17(43.58)$ & 0.5372 \\
\hline
\end{tabular}

\section{Discussion}

Nasal continuous positive airway pressure is the primary mode of therapy in preterm neonates especially in hyaline membrane disease. It reduces the need of ventilator, surfactant and invasive ventilation associated risks [4]. Use of continuous positive airway pressure (CPAP) in preterm neonates with respiratory distress reduces mortality by $66 \%$ [5]. Success rate of CPAP therapy is variable across the neonatal units. Practical 


\section{Original Research Article}

challenges during CPAP therapy in neonates are ensuring proper fixation and to avoid nasal trauma. There are various devices available which can be used as interface in CPAP therapy. Bi-nasal prongs and nasal masks are common mode of interface now a days.

Practical issues that come during therapy is balancing between proper fixation of interface to reduce CPAP failure rate and to avoid nasal trauma due to tight fixation of interface. Now a days nasal mask is considered as better option, but data showing relative efficacy are sparse [6].

Reported incidence of nasal trauma with CPAP varies widely from 20 to $73 \%$ owing to the lack of standardized assessment tools and varied gestational age of population studied [7]. In our study overall incidence of nasal trauma is $45 \%(36 / 80,46.34 \%$ in nasal prong group \& $43.58 \%$ in nasal mask group).

Emily Kieran et al [6] observed a reduced risk of intubation among preterm neonates receiving CPAP with the nasal mask ( 28 vs. $52 \%$ ) as compared to binasal prongs.

Singh $\mathbf{J}$ et al [8] concluded that the duration of CPAP was less in nasal prongs than nasal mask which was statistically significant. There was no significant difference of nasal trauma in both the groups. The babies who were less than $32 \mathrm{wks}$ and less than $1500 \mathrm{gm}$ birth weight had more frequent trauma in both the group. The severity of trauma was more as the duration of CPAP was increasing in both the groups. They concluded that nasal mask and nasal prongs cause equivalent trauma. Our study also supports the same fact.

Yong S C et al [9] compared the incidence of nasal injury with IFD nasal masks versus nasal prongs. Although the incidence of nasal injury was similar in the groups ( 35 vs. $29 \%, p=50$ ), it occurred earlier with use of nasal prongs than masks (median interquartile range) 8.0 (8.0) vs. 14.0 (18.2) days.

Our results are also comparable toChandrasekaran et al [10], who found severe nasal trauma to be more common (31\% vs $0 \%)$ among neonates in the nasal prongs group. They also concluded that there is no difference in efficacy between nasal masks and binasal prongs in delivering CPAP in premature neonates. Yet, nasal masks are associated with a lower risk of severe nasal trauma and hence, may have a role in neonates who are at risk or have developed mucosal injury with binasal prongs.
Kumar $\mathrm{G}$ et al [11] found that failure of NCPAP was noticed in $11(36.7 \%)$ patients in nasal prong group, while in nasal mask group NCPAP failure was noticed in $5(16.7 \%)$ patients. There was no statistically significant difference found in failure rate between the two groups $(\mathrm{P}=0.080)$. Median duration $(\mathrm{IQR})$ in hrs on NCPAP support was $42.5 \mathrm{hrs}$ (25-55) in nasal prong group, while in nasal mask group median duration (IQR) was 47.25hrs (36-72) with a P value of 0.181 .

Median duration (IQR) of total hospital stay was $216 \mathrm{hrs}$ (112.5-354) in nasal prong group whereas nasal mask group median duration (IQR) of total hospital stay was 264 hrs (186-456). There was a significant difference found in total duration of hospital stay between both interfaces as nasal prong group was better in terms of total hospital stay $(\mathrm{P}=0.036)$. Localized nasal complications were detected in $10(33.3 \%)$ patients in nasal prong, while in nasal mask group they were reported in $6(20 \%)$ patients. There was no significant difference $(\mathrm{P}=0.136)$.

Goel $S$ et al[12] also concluded that nasal continuous positive airway pressure failure occurred in $8(13 \%)$ of Mask group and 14 (25\%) of Prongs group but was statistically not significant (RR $0.53,95 \%$ CI $0.24-1.17$ ) $(\mathrm{P}=0.15)$. The rate of pulmonary interstitial emphysema was significantly less in the Mask group (4.9\% vs. $17.5 \%$; RR 0.28, 95\% CI 0.08-0.96; $\mathrm{P}=0.03)$. Incidence of moderate nasal trauma $(6.5 \%$ vs $21 \%)(\mathrm{P}=0.03)$ and overall nasal trauma $(36 \%$ vs $58 \%)(\mathrm{P}=0.02)$ were significantly lower in mask group than in the prongs group.

Newnam KM et al[13] conducted a three group prospective randomized experimental design to identify differences in frequency and severity of nasal injuries when comparing various interfaces used during continuous positive airway pressure (CPAP) and identified risk factors associated with injury.

Seventy-eight neonates $<1500 \mathrm{~g}$ were randomized into three groups: continuous nasal prongs; continuous nasal mask; or alternating mask/prongs. Repeated measures ANOVA with Bonferroni correction demonstrated that significantly less skin injury was detected in the rotation interface group when compared to both mask and prong groups. In the final stepwise regression model $(\mathrm{F}=$ $11.51 ; \mathrm{R}(2)=0.221 ; \mathrm{p}=0.006)$ significant predictors of skin injury included number of days on nasal CPAP ( $p$ $<0.001)$ and current mean post menstrual age $(\mathrm{p}=0$. 006). Reduced nasal injury was demonstrated using rotating mask/prong nasal interfaces. Future best practices must include precise selection of device size, 


\section{Original Research Article}

developmental and CPAP device positioning with focused skin assessment including rapid intervention for skin injury.

Based on our study we observed that there is no significant difference in efficacy of binasal prongs and nasal mask in terms of overall incidence of nasal trauma in premature neonates. We found that the grade of nasal trauma was significantly different in both groups. Babies received CPAP therapy via nasal mask had higher rate of mild trauma (grade I) as compared to nasal prong group.

Difference in rate of moderate trauma (grade II) was not statistically significant in either group. Nasal prongs were associated with higher risk of severe nasal trauma (grade III). The narrowing of nasal passage and necrosis were significantly high in babies received CPAP via nasal prongs.

The strengths of our study were its randomized design, robust methodology and use of bubble CPAP as the only pressure-generating device. Nasal injury was assessed objectively with the help of self-designed grading system. Our limitations were the inability to blind the investigator and treating team as well as considerable attrition of the study population available for the primary outcome.

\section{Conclusion}

Based on our study we conclude that the use of binasal prongs and nasal mask as interface during CPAP therapy makes no difference in overall incidence of nasal trauma in the preterm neonates. The incidence of mild trauma is more common with use of nasal mask, while nasal prongs are associated with more severe nasal trauma during CPAP therapy in preterm neonates.

Authors' Contributions- Archana Dubey designed the study protocol, recruited the participants, drafted the initial manuscript; Sunil Malik supervised data collection, assessed the outcomes and revised the manuscript; Sneha Prakash helped in designing the study, supervised data collection, analysed the results; all authors approved the final manuscript.

What this add to existing knowledge- It is well established thatbi-nasal prongs are better than single nasal and nasopharyngeal prongs for delivering continuous positive airway pressure (CPAP) in preventing need for re-intubation; but It is unclear if they are superior to newer generation nasal masks in preterm neonates requiring CPAP. Our study adds that the use of nasal masks is associated with significantly lower risk of severe grades of nasal injury.

Funding: Nil, Conflict of interest: None initiated, Perission from IRB: Yes

Consent Informed: Informed consent was obtained from all individual participants included in the study.

\section{References}

1. Mathai SS, Raju U, Kanitkar M. Management of Respiratory Distress in the Newborn. Med J Armed Forces India. 2007 Jul; 63 (3): 269-72. doi: 10.1016/ S0377-1237(07)80152-3. Epub 2011 Jul 21.

2. Polin RA, Sahni R. Newer experience with CPAP. Semin Neonatol. 2002 Oct;7(5):379-89.

3. Silverman WA, Andersen DH. A controlled clinical trial of effects of water mist on obstructive respiratory signs, death rate and necropsy findings among premature infants. Pediatrics. 1956 Jan;17(1):1-10.

4. Schmölzer GM, Kumar M, Pichler G, et al. Noninvasive versus invasive respiratory support in preterm infants at birth: systematic review and meta-analysis. BMJ. 2013 Oct 17;347:f5980. doi: 10.1136/bmj.f5980.

5. Thukral A, Sankar MJ, Chandrasekaran A, Agarwal R, Paul VK (2016) Efficacy and safety of CPAP in lowand middle-income countries. J Perinatol 36:S21-S28

6. Kieran EA, Twomey AR, Molloy EJ, et al. Randomized trial of prongs or mask for nasal continuous positive airway pressure in preterm infants. Pediatrics. 2012 Nov; 130 (5): e1170-6. doi: 10.1542/ peds. 2011-3548. Epub 2012 Oct 22.

7. Robertson NJ, McCarthy LS, Hamilton PA, Moss AL.Nasal deformities resulting from flow driver continuous positive airway pressure. Arch Dis Child Fetal Neonatal Ed 1996;75:F209-F212

8. Singh J, Bhardwar V, Chirla D. To compare the efficacy and complication of nasal prongs \& nasal mask CPAP in neonates. UMDS. January 2017;6(1) p 1392 1397.

9. Yong SC, Chen SJ, Boo NY. Incidence of nasal trauma associated with nasal prong versus nasal mask during continuous positive airway pressure treatment in very low birthweight infants: a randomised control study. Arch Dis Child Fetal Neonatal Ed. 2005 Nov; 90 (6): F480-3. Epub 2005 Jun 7. 


\section{Original Research Article}

10. Chandrasekaran A, Sachdeva A, Sankar MJ, Agarwal R, Deorari AK, Paul VK. Nasal mask versus nasal prongs in the delivery of continuous positive airway pressure in preterm infants - An open label randomized controlled trial. E-PAS. 2014: 2936: 512

11. Kumar G, Tiwari A, Shukla A, Chopra M. Study effectiveness of nasal prong and nasal mask in NCPAP in preterm neonates with respiratory distress. JMSCR. May 2017 Vol 05. Issue 05. P 21409-21415.
12. Goel S, Mondkar J, Panchal H, et al. Nasal Mask Versus Nasal Prongs for Delivering Nasal Continuous Positive Airway Pressure in Preterm Infants with Respiratory Distress: A Randomized Controlled Trial. Indian Pediatr. 2015 Dec;52(12):1035-40.

13. Newnam KM, McGrath JM, Salyer J, et al. A comparative effectiveness study of continuous positive airway pressure-related skin breakdown when using different nasal interfaces in the extremely low birth weight neonate. Appl Nurs Res. 2015 Feb;28(1):36-41. doi: 10.1016/j.apnr.2014.05.005. Epub 2014 Jun 5.

\section{How to cite this article?}

Dubey A, Malik S, Sneha Prakash. A comparative study of incidence and severity of nasal complications while using nasal prongs and nasal mask as CPAP interface in preterm neonates: A Randomized Control trial.Int J Pediatr Res. 2019; 6 (04):177-182.doi:10.17511/ijpr.2019.i04.05 